\title{
Manifestações Neurológicas e COVID-19
}

\section{Neurological Manifestations and COVID-19}

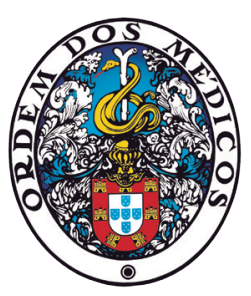

Andreia COSTA $\triangle^{1,2}$, André SILVA-PINTO3,4,5

Acta Med Port 2020 Dec;33(12):787-788 - https://doi.org/10.20344/amp.14773

\section{Palavras-chave: COVID-19; Manifestações Neurológicas; SARS-CoV-2}

Keywords: COVID-19; Neurologic Manifestations; SARS-CoV-2

$\mathrm{O}$ advento da pandemia da COVID-19 despertou interesse da comunidade científica sobre o possível neurotropismo do SARS-CoV-2 e da extensão do seu potencial dano direto e/ou indireto no sistema nervoso. Um crescente número de publicações tem reportado o envolvimento neurológico na COVID-19 mas permanecem muitas interrogações quanto à sua fisiopatologia (diretamente pelas propriedades neuroinvasivas do vírus ou consequência indireta da disfunção multiorgânica e bioquímica) e ao seu impacto a longo prazo.

O SARS-CoV-2 apresenta grande homologia com o SARS-CoV, que é comprovadamente neurotrópico - ambos utilizam proteínas da superfície para se ligarem ao recetor da enzima de conversão de angiotensina-2; a localização deste recetor parece determinar o tropismo celular do vírus no sistema nervoso central (neurónios, microglia, astrócitos e oligodendrócitos). O mecanismo pelo qual o vírus penetra no sistema nervoso permanece especulativo mas destacam-se as hipóteses de transferência transsinática por neurónios infetados (incluindo a porta de entrada pelo bolbo olfativo) e de disseminação pela barreira hematoencefálica quer por infeção das células endoteliais vasculares quer dos leucócitos. ${ }^{1}$

Os estudos relatam prevalências de manifestações neurológicas muito díspares: entre 3\% e 35\%, afigurando-se mais frequentes no doente grave ou crítico. As manifestações neurológicas iniciam-se geralmente entre o primeiro e o $14^{\circ}$ dia após o início dos sintomas respiratórios. $\mathrm{Na}$ maioria dos casos, não tem sido possível o isolamento do vírus no líquido cefalorraquidiano crendo-se que a disseminação ao sistema nervoso central seja transitória e que a carga vírica seja inferior à capacidade de deteção dos testes disponíveis. ${ }^{2}$

Os sintomas neurológicos mais comuns da infeção por SARS-CoV-2 são a cefaleia, a anosmia e a ageusia. ${ }^{1}$ A cefaleia é um sintoma inespecífico que acomete até um terço dos doentes e a sua patofisiologia permanece desconhecida embora a ativação de neurónios nociceptivos por mecanismos neuroinflamatórios seja plausível. A anosmia e ageusia com prevalências de até $88 \%$ em algumas séries europeias, embora não específicas, no atual contexto e na ausência de sintomas de obstrução nasal e rinite, podem ser marcadores precoces para o diagnóstico de doentes pauci-sintomáticos. ${ }^{3}$

Outras manifestações neurológicas incluem doença cerebrovascular aguda, infeção do sistema nervoso central, encefalopatia, crises epiléticas e manifestações neuromusculares. ${ }^{1}$ Vários estudos sugerem existir um aumento do risco de doença cerebrovascular em indivíduos infetados: nos idosos com múltiplos fatores de risco vascular mas também em indivíduos com menos de 50 anos, ${ }^{4}$ possivelmente por mecanismos relacionados com inflamação sistémica, hipercoagulabilidade e vasculopatia. Embora não exista ainda nenhum caso em que comprovadamente há infeção do sistema nervoso central pelo SARS-CoV-2, essa possibilidade tem sido levantada em alguns casos clínicos. Importa realçar que em doentes com COVID-19 que se apresentam com sintomas de encefalite e/ou meningite outros patogéneos devem ser excluídos. A encefalopatia de causa tóxico-metabólica é uma complicação frequentemente descrita, possivelmente originada por mecanismos inflamatórios que desencadeiam tempestade de citocinas, sépsis e disfunção renal. Crises epiléticas sintomáticas agudas clínicas ou subclínicas podem também ser desencadeadas por alterações metabólicas, hipóxia e disfunção de múltiplos órgãos, mas também por doença neurológica primária concomitante ou ainda como efeito adverso de fármacos (antibioterapia, neurolépticos, entre outros). No que concerne às manifestações neuromusculares, têm sido descritos vários casos da síndrome de Guillain-Barré; as alterações neurológicas surgem dias a semanas após a infeção primária por SARS-CoV-2 ou sincronamente com as manifestações respiratórias. ${ }^{5}$

Os artigos são unânimes no que diz respeito à relação entre doença mais grave e maior incidência de alterações neurológicas: cerca de $14 \%$ dos doentes admitidos em unidades de cuidados intensivos (nível três) apresentam manifestações neurológicas antes de intervenção terapêutica,

1. Serviço de Neurologia. Centro Hospitalar e Universitário de São João. Porto. Portugal.

2. Departamento de Neurociências Clínicas e Saúde Mental. Faculdade de Medicina. Universidade do Porto. Porto. Portugal.

3. Serviço de Doenças Infeciosas. Centro Hospitalar e Universitário de São João. Porto. Portugal.

4. Departamento de Medicina. Faculdade de Medicina. Universidade do Porto. Porto. Portugal.

5. Grupo I\&D em Nefrologia e Doenças Infeciosas. I3S - Instituto de Investigação e Inovação em Saúde. Universidade do Porto. Porto. Portugal.

$\square$ Autor correspondente: Andreia Costa. agcosta@chsj.min-saude.pt

Recebido: 06 de julho de 2020 - Aceite: 10 de setembro de 2020 | Copyright @ Ordem dos Médicos 2020 
atingindo os $67 \%$ após sedação e desmame do ventilador, nomeadamente sinais de primeiro neurónio generalizados e síndrome confusional aguda (com agitação e/ou alterações das funções executivas). Dos 13 doentes críticos que realizaram ressonância magnética cranioencefálica numa série, oito apresentavam captação de contraste leptomeníngeo, o que é sugestivo de lesão da barreira hemato-encefálica, e todos os 11 doentes submetidos à sequência de perfusão apresentavam hipoperfusão frontotemporal bilateral; três doentes assintomáticos apresentavam lesões isquémicas de novo. ${ }^{3}$

Da nossa experiência profissional, resulta claro que a síndrome confusional aguda é frequente em doentes com COVID-19, e de difícil controlo; os estudos complementares raramente mostram alterações específicas além de encefalopatia no eletroencefalograma e os exames de imagem não têm, na sua maioria, alterações agudas. Acrescenta-se ainda que se desconhece o efeito do SARS-CoV-2 a longo prazo no sistema nervoso central, sobretudo nos doentes com COVID-19 grave e com longos períodos de síndrome confusional.

Os doentes com patologia neurológica têm frequentemente doenças complexas, múltiplas comorbilidades e fatores de risco vascular, são na sua maioria idosos, muitos dos quais institucionalizados, alguns padecem de insuficiência respiratória de causa neuromuscular e outros en-

\section{REFERÊNCIAS}

1. Zubair AS, McAlpine LS, Gardin T, Farhadian S, Kuruvilla DE, Spudich S. Neuropathogenesis and neurologic manifestations of the coronaviruses in the age of coronavirus disease 2019: a review. JAMA Neurol. 2020:77; 1018-27.

2. Espíndola OM, Siqueira $M$, Soares $C N$, Lima $M$, Leite $A$, Araujo $A Q$, et al. Patients with covid-19 and neurological manifestations show undetectable sars-cov-2 RNA levels in the cerebrospinal fluid. Int $\mathrm{J}$ Infect Dis. 2020:96;567-69.

3. Mao L, Jin H, Wang M, Hu Y, Chen S, He Q, et al. Neurologic contram-se sob tratamento imunossupressor. Estas, entre outras caraterísticas, tornam-nos particularmente vulneráveis ao desenvolvimento de COVID-19 grave. Existem já registos nacionais e internacionais que pretendem reunir os dados de doentes com manifestações neurológicas e os doentes com doença neurológica com COVID-19 com o objetivo de fomentar o conhecimento neste campo. Destaca-se ainda, em várias áreas da Medicina (esclerose múltipla, doenças cerebrovasculares, doenças neuromusculares), o desenvolvimento de recomendações para a manutenção do cuidado ao doente neurológico nesta nova era.

Em conclusão, estamos ainda longe de perceber o impacto global da COVID-19 e a extensão e prognóstico das suas manifestações neurológicas. Os estudos observacionais publicados incluem poucos doentes, sem comparador e, nalguns casos, com erros metodológicos. É necessário promover iniciativas robustas de investigação clínica; é premente continuar a diagnosticar e tratar adequadamente os doentes com doenças neurológicas, com e sem infeção por SARS-CoV-2.

\section{FONTES DE FINANCIAMENTO}

Este trabalho não recebeu qualquer tipo de financiamento ou subsídio por entidades do sector público ou privado.

manifestations of hospitalized patients with coronavirus disease 2019 in Wuhan, China. JAMA Neurol. 2020:77;1-9.

4. Oxley TJ, Mocco J, Majidi S, Kellner CP, Shoirah H, Singh IP, et al. Large-vessel stroke as a presenting feature of COVID-19 in the young. N Engl J Med. 2020:382; e60.

5. Whittaker A, Anson M, Harky A. Neurological manifestations of COVID-19: a systematic review and current update. Acta Neurol Scand. 2020:142;14-22. 